1649 Session

\title{
Promoting Faculty Development with ASEE/NASA Fellowship Programs - Parametric Study of Laser Beam Cutting (LBC) Processes - A Case Study
}

\author{
Alok K. Verma, Gary R. Crossman \\ Department of Engineering Technology \\ Old Dominion University \\ Carl J. Voglewede, Thomas J. Burns \\ Technology Development and Integration Branch \\ NASA Langley Research Center
}

\begin{abstract}
American Society for Engineering Education (ASEE) and National Aeronautics and Space Administration (NASA) offer a joint program for faculty and research development. This program known as ASEE/NASA Faculty Fellowship program offers opportunities for professional development for Engineering Technology faculty. This paper discusses one such experience involving applied research at NASA Langley Research Center, which resulted in professional development of the faculty member while enhancing the undergraduate curriculum in Engineering Technology.
\end{abstract}

\section{Introduction}

Success in an Engineering Technology programs has been traditionally evaluated based upon three factors namely, Teaching, Research and Service. While the relative ranking of these factors is arguable $^{1,2}$, it is the research (and the associated requirement of publication), which causes great anxiety for faculty in ET programs. This is especially true, in view of increasing emphasis placed on the research and publication by the ET programs in the nation. A number of articles have been written on the opportunities available for faculty development ${ }^{3,4,5,6}$. Most of these publications discuss the more common approaches for faculty development like participation in conferences, continuing education programs and internships in industry. This article discusses a faculty fellowship program, which faculty members in an undergraduate engineering technology program can use for professional growth.

The ten-week summer faculty fellowship program offered by ASEE and NASA provides an ideal setting for faculty development. These programs can also enhance learning experience of undergraduate students in the ET programs through direct involvement in applied research projects. 
A case study for research in the laser cutting process is presented. Kerf quality is often a critical parameter during this process. The quality of kerf depends upon several controllable and uncontrollable variables. For the laser beam cutting process, the controllable variables include: feed rate, power level, number of passes and frequency. Operational regions for this process have been explored while changing one variable at a time. A Specimen was prepared from copper sheet of 0.001-inch thickness. Material properties and composition of the specimen were confirmed with spectrometer tests. Kerf roughness was assessed by measuring peak-to-valley distance, $\mathrm{R}_{\max }$ under a microscope. Digital photographs of kerf roughness and scanning electron micrographs of the specimen were prepared.

\section{Research Environment in ET Programs}

Traditionally, ET programs have placed a larger emphasis on teaching compared to research. This is especially true for programs that offer only undergraduate education in engineering technology. Consequently a number of faculty have been hired primarily for teaching. At these institutions, a Master's degree is the terminal degree required for the faculty. One can argue that the research environment in most of these programs is not conducive to the generation of research and publications. Among the reasons cited are the lack of graduate students and lack of faculty with the terminal degree. During the last decade, we have seen a shift in this paradigm. An increasing number of institutions now require externally funded research and journal publication by the faculty. This changing research environment has created pressure on faculty to explore new opportunities for faculty development.

\section{Faculty Development in ET Programs}

The need to be current in one's field is critical for faculty in engineering technology programs since these faculty are often involved in industrial projects as well as applied research ${ }^{7,8,9}$. The professional development needs are generally met by participation in conferences and continuing education programs. In addition to participation at conferences, some opportunities for faculty internships are also available at selected companies. This paper discusses a unique faculty development opportunity available to ET faculty.

\section{ASEE/NASA Faculty Fellowship Program}

ASEE and NASA jointly offer a Faculty Fellowship Program (NFFP), which provides ten weeks of experience at one of the NASA's facilities. This opportunity for professional development is available to all engineering technology faculty. The selection is based upon recommendations from the place of employment and area of research interest. This program is jointly managed by ASEE and the Universities Space Research Association (USRA). The NFFP combines aspects of two successful former and long running NASA programs, the NASA/ASEE Summer Faculty Fellowship Program and the NASA/USRA Joint Venture (JOVE) program. 
The NFFP is designed to give college and university faculty members a rewarding personal, as well as, enriching professional experience. The program varies slightly at each center to accommodate the needs of the NASA Center, however, the common features of the program at each center include:

- Short courses and workshops

- Tours of the center

- Seminars and retreats

- Program evaluation

- Social activities for participants and families

The NASA Faculty Fellowship Program (NFFP) offers hands-on exposure to NASA's research challenges through 10-week summer research residencies at participating NASA research centers for fulltime science and engineering faculty at U.S. colleges and universities. Participants work closely with NASA colleagues on research that is important to NASA's five strategic enterprises.

\section{Example of Faculty Participation}

During summer 2003, Professor Verma participated in the ASEE/NASA Faculty Fellowship program at NASA Langley Research Center in Hampton, Virginia. Professor Verma is a faculty member in the engineering technology department at Old Dominion University in Norfolk, Virginia. NASA Langley Research Center is located only 20 miles from the university and thus was the obvious choice. However, the program offers travel and relocation allowances for faculty who may have to move during the ten-week period. His research interests lie primarily in the manufacturing area and therefore he contacted the fabrication branch in the system's competency. The fabrication branch had recently acquired a dual laser cutting system and a water jet cutting system. His research experience in process optimization and interest in laser cutting and the water jet cutting process resulted in a match of the research areas. During the ten-week period, he collaborated with several NASA employees in the fabrication branch and conducted parametric study of the laser and water jet cutting process. The results related to laser beam-cutting process is presented in this paper.

\section{Case Study - Laser Beam Cutting Process (LBC)}

Laser beam cutting has become immensely popular in the manufacturing industry for the benefits it offers. Laser beam cutting uses a monochromatic and coherent beam of light focused by a optical lens to melt and evaporate material. A typical set-up for this cutting process is shown in Figure1 below. 


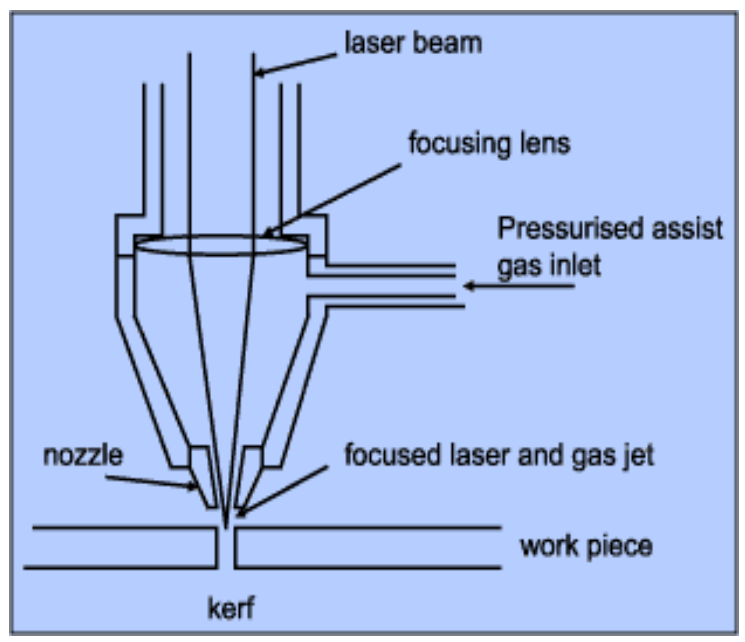

Figure 1. Laser Processing Setup

\section{a. Dual Laser Cutting System by Photo Machining, Inc.}

The laser cutting was done on a dual laser cutting system by Photo Machining, Inc using a 7-Watt solid-state diode pumped laser. The laser system has a table size of 36x24 inches and a resolution of 0.1 micron in the $\mathrm{X} \& \mathrm{Y}$ direction with a resolution of 1.0 micron in the $\mathrm{Z}$ direction. The higher power $\mathrm{CO} 2$ laser was not used during this study. Figure 2 shows the laser system and the operator at NASA's Langley Research Facility.

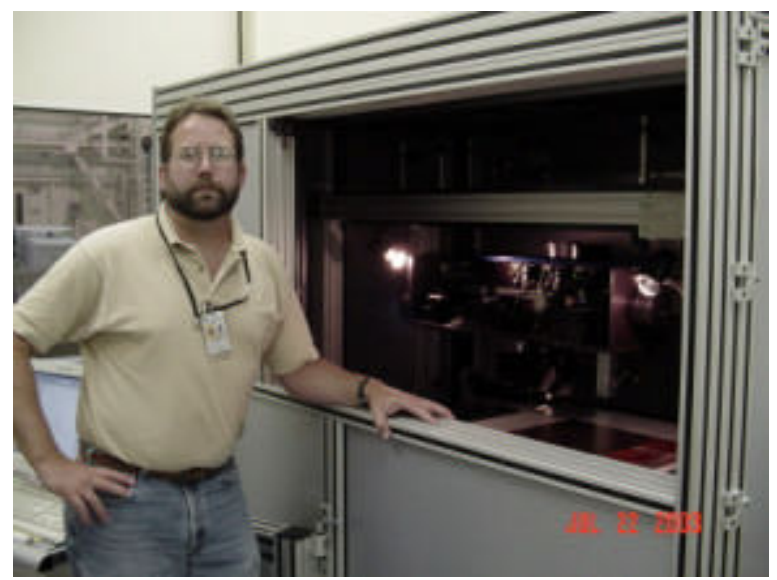

Figure 2. Laser Cutting System

\section{b. Cutting Parameters}

Kerf quality is an important quality characteristic from the customer's viewpoint. Laser cutting has 
become extremely popular during the last decade for cutting various types of materials. The reduction in the cost of lasers along with beam quality and reliability have made this process more desirable in comparison to traditional methods like mechanical shearing. In laser cutting, kerf quality depends on a number of parameters. Important among these are frequency, feed rate, number of passes and power level. Table 1 lists some of these parameters and the levels at which experiments were conducted to measure kerf roughness.

\begin{tabular}{|l|l|l|l|l|l|l|l|}
\hline Parameters & Tvpe & Level & Level & Level & Level & Level & Level \\
\hline Roughness & Response & \multicolumn{7}{|c|}{ Mean Peak to Valley Roughness - Rmax } \\
\hline Kerf Width & Response & \multicolumn{7}{|c|}{ Mean Kerf Width - W - inches } \\
\hline Frequency KHz & Variable & 25 & 35 & 45 & 55 & 65 & 75 \\
\hline Feed Rate in/sec & Variable & 0.5 & 1.0 & 5 & 10 & 15 & 20 \\
\hline $\begin{array}{l}\text { Number of } \\
\text { Pacsec }\end{array}$ & Variable & 1 & 5 & 10 & 15 & 20 & \\
\hline Power Level & Constant & \multicolumn{7}{|c|}{$100 \%$} \\
\hline Material & Constant & \multicolumn{7}{c|}{ Copper sheet, $\mathrm{t}=0.001$ inch } \\
\hline
\end{tabular}

Table 1. Cutting Parameters

\section{c. Kerf Quality Measurement}

Kerf quality can be expressed by kerf roughness. The roughness of the cut edge can be measured and expressed either as maximum peak to valley roughness or mean roughness as shown in Figure 3. Mean surface roughness can be measured with a stylus-based profilometer, if the thickness of material is large enough to allow for stylus movement. Sample materials for this study were cut from copper foil, 0.001 inch thick. The maximum peak to valley measurement at four locations were taken and averaged to calculate the kerf roughness.

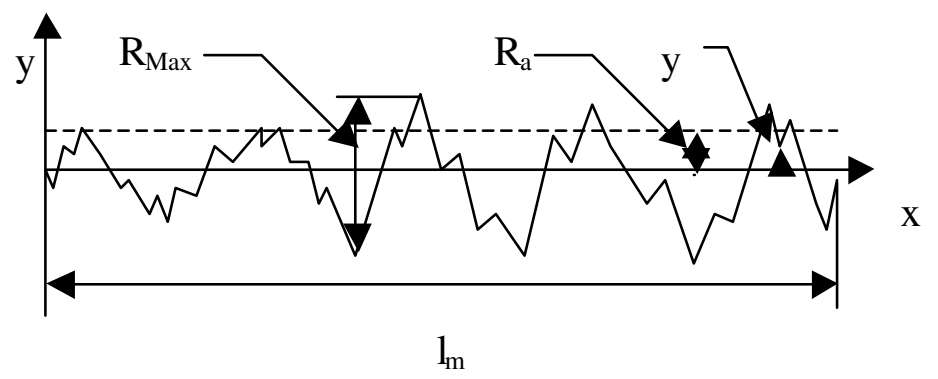

Figure 3. Kerf Roughness Measurement. 
The copper foil samples were cut using the laser at parameter settings indicated in Table 1 and observed with an optical microscope to obtain peak to valley roughness. A typical kerf profile photograph and the expression for mean surface roughness is shown in Figure 4.

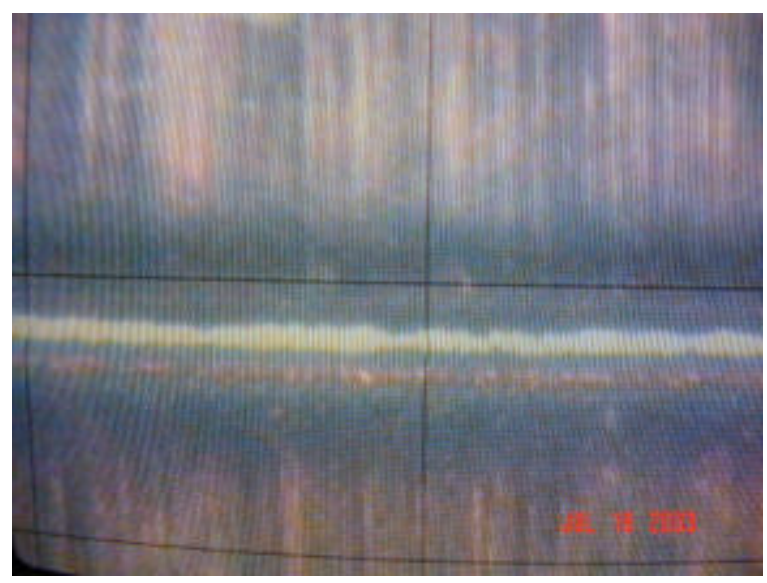

Max. Peak to Valley Roughness $=\mathrm{R}_{\text {Max }}$

Mean Roughness $=R_{a}=\frac{1}{l_{m}} \int_{0}^{l_{m}}|y| d x$

Figure 4. Kerf Quality at N=5, f=50 K Hz, FR=20 in/sec.

\section{d. Surface Roughness vs. Frequency}

Figure 5 shows the plot of kerf roughness vs. frequency. As frequency increases, kerf roughness decreases and this reduction is more prominent at higher frequency levels.

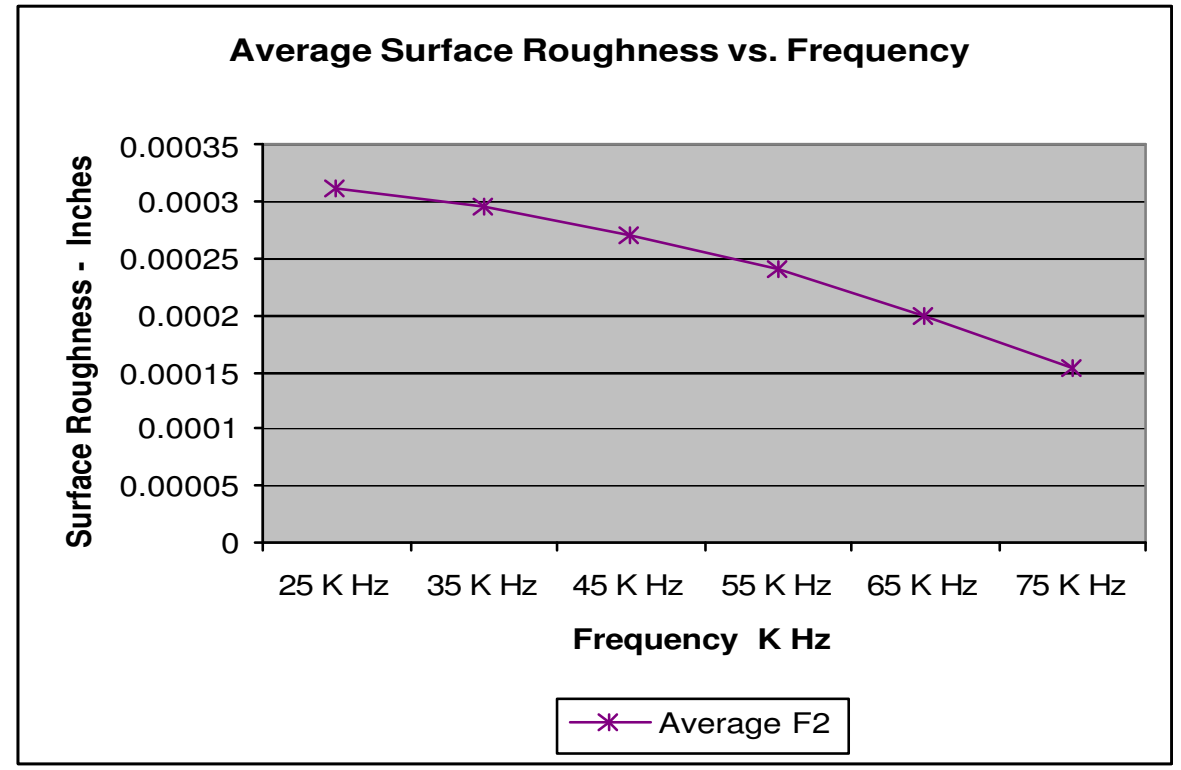

Figure 5. Surface Roughness vs. Frequency 


\section{e. Kerf Width vs. Feed Rate}

Figure- 6 shows the plot of kerf width vs. feed rate. As feed rate increases, kerf width decreases and this reduction is more prominent at lower feed rates. At higher feed rates there is no effect on the kerf width. The kerf width is also higher for higher repetition rates.

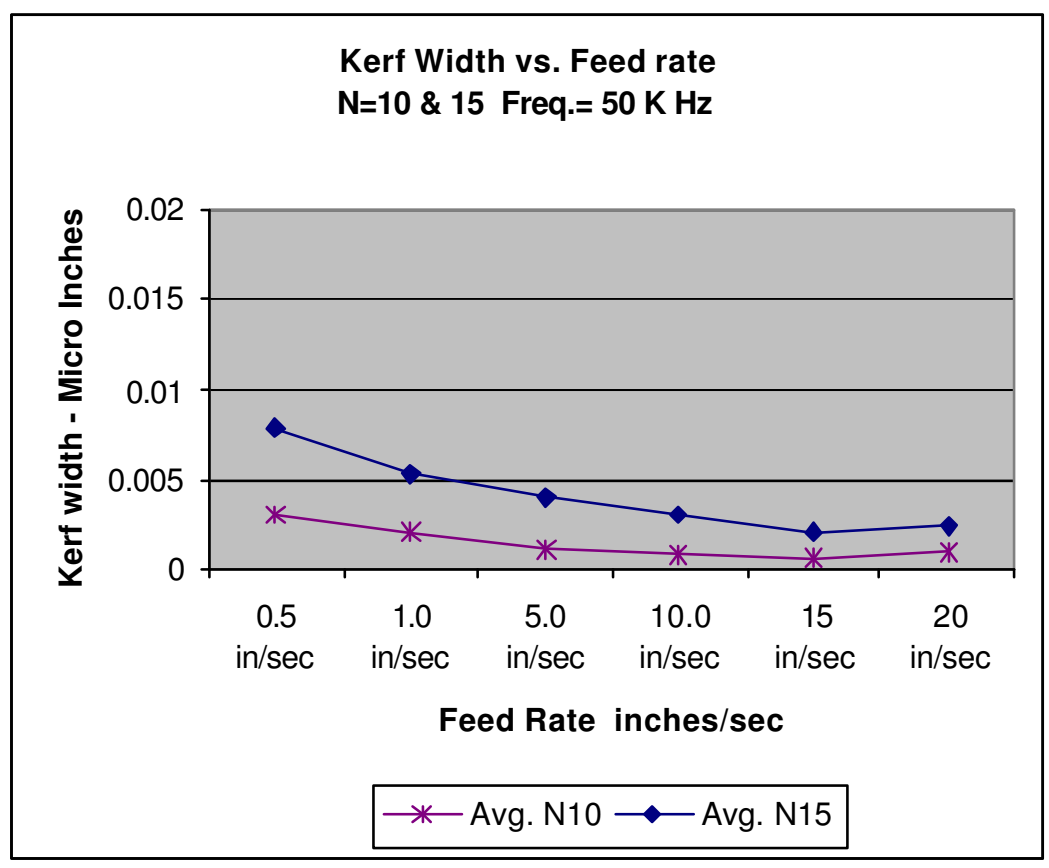

Figure 6. Kerf Width vs. Feed Rate

\section{Impact on Research \& Curriculum Development}

The summer experience resulted in a research proposal being submitted to the fabrication branch for the optimization of laser beam cutting and water jet cutting processes. In addition the results obtained during the summer have been presented at two conferences. The impact on curriculum development was also notable. The Advanced Manufacturing Processes course (MET-410) in the Mechanical Engineering Technology curriculum was modified to include information obtained during the internship program. In addition, the seminars organized by the program on various topics expanded the author's research interests. Collaboration with other NASA employees proved invaluable. The contacts and networking made possible due to this program have opened a number research collaboration opportunities.

Research experiences as described above provide an opportunity for faculty development andhelp faculty maintain currency in their field of expertise. The educational experience of students is enhanced as faculty bring their research experience to classroom. New courses often are by product of such experiences which in turn broaden the learning experience of students. For faculty, such experiences offer personal growth and job satisfaction. 


\section{Summary}

Faculty members in undergraduate engineering technology programs have several opportunities for research and professional development. In face of the increasing emphasis on research and publication, lack of graduate programs and graduate students is no longer a valid argument. The ten-week faculty fellowship program offered by ASEE and NASA offers a unique opportunity for professional development. Faculty in ET programs can use it as a stepping-stone for exploring research opportunities in various areas. The fellowship also provides opportunities for meeting faculty members from other institutions and exploring collaborative research with them. These experiences also result in curriculum development and enhancement of undergraduate learning experience.

\section{Bibliography}

1. Pagano, Mark, AThe success of Engineering Technology Educators-Has a Paradox Emerged? @ Proceedings of the ASEE annual conference at University of Illinois at Urbana-Champaign, June 20-23,1993.

2. Rosenfeld,L., \& Long, B. W., @An Evaluation System for measuring faculty performance.@, ACA Bulletin, 75, pages, 44- 51,1991.

3. Buchanan, Walter W., Expectations for faculty development in engineering technology. @ Proceedings of the ASEE annual conference, Milwaukee, June 15-18,1997.

4. Murtos, Nickos J.; Allen, Emily L., Assessing the effectiveness of a faculty development program. @ Proceedings of the Frontiers in Education conference, Puerto Rico, November 10-13,1999.

5. Felder, Richard M., Faculty development: getting the sermon beyond the choir. @ Proceedings of the ASEE annual conference, Seattle, June 28- July 1, 1998.

6. Terry, Ronald E., Sandholz, Kurt, Rosenfeld, L., \& Long, B. W., Non-traditional faculty development program. @ Proceedings of the Frontiers in Education conference, Puerto Rico, November 10-13,1999.

6. Verma, A. K., Crossman, G. R. \& Lin, C., Bringing industry and Academia together with Applied Research Projects@Proceedings of the ASEE annual conference, June 1994.

7. Crossman, G. R. \& Marchello, J. M., The Engineering Technology Clinic at Old Dominion University- Meeting Professional Needs. Industry and Higher Education. ., March, 1989.

8. Verma, A. K. \& Hackworth, J., Design and Construction of an Automated Battery Testing Machine. @ International Mechanical Engineering Congress and Exposition, 1999.

9. Homkes, R. A., Writing and Publishing Your Way to tenure. @ Proceedings of the ASEE annual conference, June 1996. 10. Fulton, Carol, Licklider, Barbara L., Re-engineering faculty development: lessons LEA/Rned, @ Proceedings of the ASEE annual conference, Seattle, June 28- July 1, 1998.

\section{Biography}

\section{ALOK K. VERMA}

Alok K. Verma is Associate Professor and, Director of the Automated Manufacturing Laboratory at Old Dominion University. He joined the Engineering Technology Department at Old Dominion University in 1981. Since then, he has served as department chairman and interim associate dean of the college. Alok is a licensed professional engineer in the state of Virginia, a certified manufacturing engineer and has certification in Lean Manufacturing and Six Sigma. His 
publications are in the areas of Lean Manufacturing, Process Automation and improvement, Advanced Manufacturing Processes, CAD/CAM, and Robotics. He is serving as the associate editor for the International Journal of Agile Manufacturing. Alok has developed the training program in Lean Enterprise for Northrop Grumman Newport News Apprentice School and continues his participation through a joint National Shipbuilding Research Program (NSRP) project to develop and design new simulation tools for Lean enterprise training. He is active in ASME, ASEE and SME.

\section{GARY R. CROSSMAN}

Gary Crossman is a Professor of Engineering Technology at Old Dominion University in Norfolk, Virginia. He also serves as Chair of the Engineering Technology Department. Professor Crossman received his B.S. degree from the U.S. Merchant Marine Academy in 1964 and his M.E. degree in 1970 from Old Dominion University, where he has served on the faculty for over 30 years. Professor Crossman is a Fellow of ASEE and the recipient of the

James H. McGraw Award for leadership in engineering technology education. He is also a registered Professional Engineer in Virginia. 